\title{
Leprosy: prevalence and factors associated with seropositivity for anti- NDO-LID antibodies in children under 15 years of age*
}

\author{
Luciane Cardoso Gomes ${ }^{1}$, Denise da Costa Boamorte Cortela ${ }^{2}$, Eliane Aparecida Silva ${ }^{3}$, \\ Ageo Mário Cândido da Silva ${ }^{4,5}$, Silvana Margarida Benevides Ferreira ${ }^{1,5}$
}

DOI: http:/ / dx.doi.org/10.1590/abd1806-4841.20197543

\begin{abstract}
BACKGROUND: A high prevalence of leprosy among children under 15 years of age indicates the need to implement actions to prevent new cases of the disease. Serological tests have been developed with the aim of helping to control the disease by indicating, through seropositivity, the presence of infection.

ОвлЕстіVE: To analyze the prevalence and factors associated with seropositivity rate for anti-NDO-LID antibodies in children under 15 years of age, contacts of leprosy patients.

MethoD: We performed a cross-sectional study with 210 children under 15 years old of age. Of them, 50 were household contacts and 160 were neighborhood contacts living in the municipality of Cuiabá, state of Mato Grosso, in 2016. The data were obtained from interviews and the NDO-LID rapid test during home visits from February to July 2016. For the analysis, we used Poisson regression and prevalence ratio.

RESULTS: Seropositivity in contacts was 6.2\%. Variables associated with seropositive tests included sex (PR = 1.05; 95\% CI: 1.01 1.08), race/skin color ( $\mathrm{PR}=0.95 ; 95 \% \mathrm{CI}: 0.90$ - 0.99), residence area $(\mathrm{PR}=1.05 ; 95 \% \mathrm{CI}: 1.01$ - 1.09$)$, and number of people per household (PR = 1.06; 95\% CI: 1.02 - 1.08).

STUDY Limitations: The small sample size, besides leading to wide confidence intervals, may have been a limitation for the identification of associated factors.

ConcLusions: The prevalence of seropositivity was high. Variables associated with NDO-LID seropositivity included female sex, not to be brown skinned, live in urban areas, and live with five or more people.
\end{abstract}

Keywords: Adolescent; Child; Leprosy; Risk factors; Serologic tests

\section{INTRODUCTION}

Leprosy is a chronic and highly disabling transmissible disease caused by infection with Mycobacterium leprae ( $M$. leprae). The disease affects the skin and peripheral nerves. ${ }^{1}$

Children are considered a high-risk group for infection and disease due to the incomplete development of their immune system, especially those exposed to the bacillus in their home or neighborhood environment. . $^{2-4}$

The disease, when it affects children under 15, can affect growth and development, cause physical limitations and sequelae, and lead to hospitalizations. It can also cause changes in the daily life of patients and their families, affect school life, cause losses in social relationships, jeopardize recreational activities, and even trigger psychological problems. ${ }^{5}$

In 2015, 18,796 new cases of leprosy were recorded in children under 15 years of age worldwide. ${ }^{6}$ Brazil, in that same year, had 1,942 new cases in that same age group and reported an annual detection rate of 4.28/100 thousand population between zero to 14 years of age, which is considered high according to parameters

\footnotetext{
Received on 15 August 2017.

Accepted on 05 June 2018

Study conducted at the Master of Science in Nursing Program, Universidade Federal de Mato Grosso, Cuiabá, MT, Brazil. Financial support: Brazilian Ministry of Health. Public Call No. 20_2013.

Conflict of interests: None.

Master of Science in Nursing Program, Universidade Federal de Mato Grosso, Cuiabá, MT, Brazil.

Faculty of Health Sciences, Universidade do Estado de Mato Grosso, Cáceres, MT, Brazil.

Division of Research and Education, Instituto Lauro de Souza Lima, Bauru, SP, Brazil.

Master of Science in Collective Health Program, Universidade Federal de Mato Grosso, Cuiabá, MT, Brazil.

Master of Science in Environment and Health Program, Universidade de Cuiabá, Cuiabá, MT, Brazil.

MAILING AdDRESS:

Luciane Cardoso Gomes

E-mail: luciane.arapai@outlook.com

(C2019 by Anais Brasileiros de Dermatologia
} 
of the Brazilian Ministry of Health. ${ }^{1,6,7}$ The state of Mato Grosso remains hyperendemic, and this pattern of hyperendemicity has been observed in the last ten years in Cuiabá, a region with a high concentration of cases and, consequently, at greater risk for the disease. ${ }^{8}$

Leprosy control has been a challenge, and several serological tests have been developed with the aim of helping to control the disease, among them, the anti-natural octyl disaccharide-leprosy IDRI diagnostic (NDO-LID).

NDO-LID is a rapid immunochromatographic assay with a simple add-and-read procedure that, by identifying specific antibodies against the bacillus that causes the disease, allows the early detection of M. leprae infection. ${ }^{9,10}$ Its use in contacts of leprosy patients has been suggested since they are a population at high risk for the disease. ${ }^{9,10}$

The use of NDO-LID rapid test among the population under 15 years of age is rare and little is known about the factors associated with positive results. Most research with the tests is performed on populations older than 15 years of age and restrict the approach to intrahousehold contacts. ${ }^{9-14}$

The present study aims to analyze the prevalence and factors associated with seropositivity rates in the anti-NDO-LID rapid test in children under 15 years of age, contacts of leprosy patients.

METHOD

We performed a cross-sectional study conducted with children under 15 years of age, contacts of leprosy patients, living in the municipality of Cuiabá, state of Mato Grosso, Brazil, in 2016.

The subjects were selected from the initial identification of 45 cases of leprosy in children under 15 years of age reported in the Brazilian Notifiable Diseases Surveillance System, Mato Grosso division (SINAN-MT) from 2014 to 2015. Of these cases, 5 patients were not found. From the 40 remaining cases (75\% treated and 25\% under treatment), we were able to identify 228 contacts younger than 15 years. Patients who failed to attend the health unit at a scheduled date after two home visits ( $\mathrm{n}=8$ contacts), and neighborhood contacts who were also household contacts $(n=10)$ were also excluded, making a total of 210 analyzed children under the age of 15 years (50 household contacts and 160 neighborhood contacts residing within a radius of up to 100 meters from the residence of a leprosy patient under 15 years of age, Figure 1 ).

The data collection was carried out by nursing and medical professors and students from February to July 2016. We used a structured questionnaire to obtain socioeconomic, demographic, and cohabitation information from leprosy patients. When necessary, the interviews were done with parents and/or legal guardians.

The NDO-LID rapid test was performed from a drop of whole blood loaded into the sample well of the device, followed by the injection of 2-3 drops of buffer solution, with a visual readout of the result within 20 minutes by two independent readers. A single colored line in the results window indicated a negative result. Two colored lines, on the other hand, indicated a positive result. If there were no visible colored lines, the result was considered invalid and the test was repeated (Figure 2).

We conducted independent statistical analyzes for household and neighborhood contacts. The result of the NDO-LID test was con- sidered as a dependent/response variable, which was categorized as positive or negative. Socioeconomic and demographic variables (age, sex, race/skin color, residence area, and housing situation) and co-habitation variables (number of people per household, number of children under 15 years per household, and length of residence) were considered as independent/exposure variables.

Race/skin color was categorized as brown and non-brown (white, black, Asian, and indigenous), and was self-identified during the interview. ${ }^{15}$ The data were double entered onto EpiInfo version 3.5.2. For the statistical analysis, we used EpiInfo version 7 and Stata version 8.0. Seropositivity prevalence was calculated separately for household contacts, neighborhood contacts, and all contacts together.

Cuiabá-MT in the period between Sep. 01, 2014 to Dec. 31, 2015

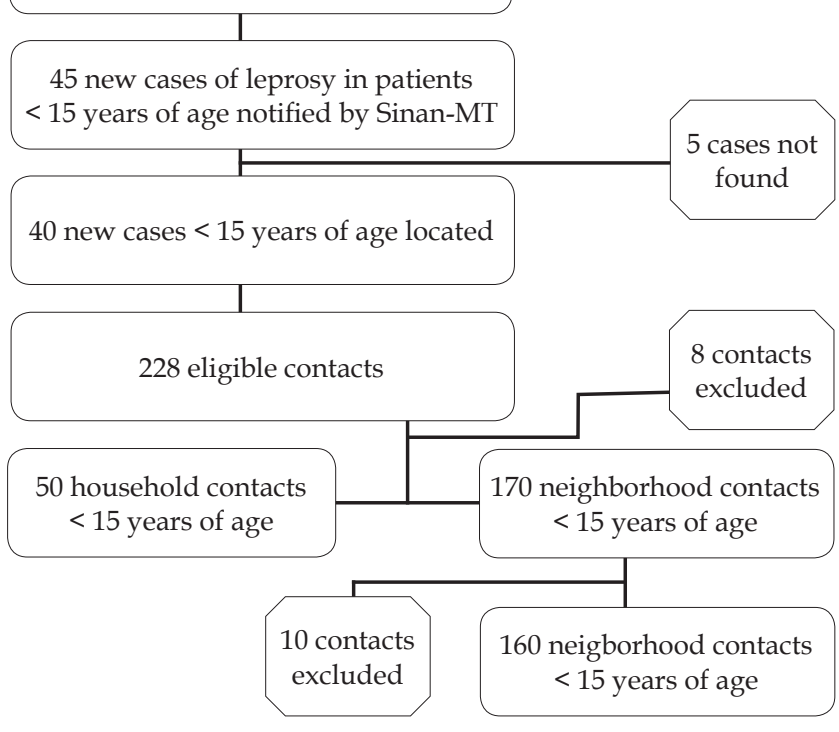

Figure 1: Flowchart of the population selection process

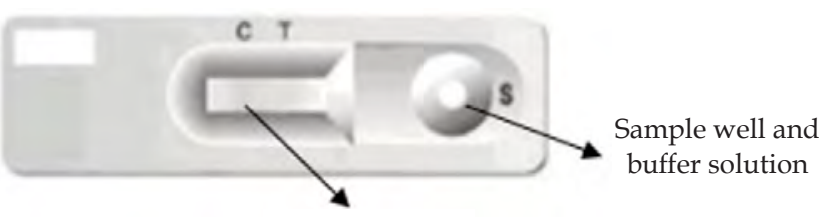

Result window

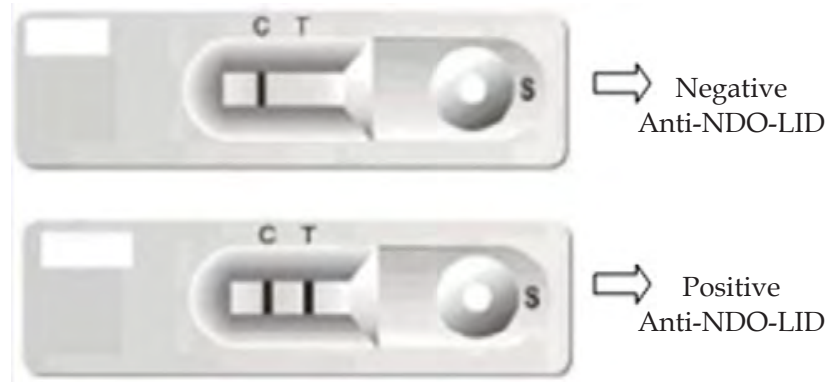

FIGURE 2: Schematic model of the anti-NDO-LID rapid test and test presentation with negative and positive results 
In order to identify associations between dependent and independent variables, we used prevalence ratio (PR) with confidence interval set at 95\% (95\% CI) using the Mantel-Haenszel test or Fisher's exact test. The variables that had $p$ values smaller than or equal to 0.20 in this bivariate analysis were adjusted in the Poisson multiple regression model, being gradually removed by the backward method. Only the variables that had a statistical significance of $5 \%(p<0.05)$ were included in the final multiple model.

The present study is linked to a matrix project approved by the Research Ethics Committee of the Universidade de Cuiabá, process $n^{\circ} 443.830$, November 2013, and had partnerships with the Instituto Lauro de Souza Lima, from São Paulo, Universidade de Cuiabá, and the Municipal Health Department of Cuiabá.

\section{RESULTS}

Seropositivity rate for anti-NDO-LID antibodies in children under 15 years of age was $4.0 \%$ among household contacts, $6.9 \%$ among neighborhood contacts, and $6.2 \%$ among all contacts together (household plus neighborhood contacts). Regarding household contacts, $62.0 \%$ lived with multibacillary leprosy patients (MBs) under 15 years of age, and 56.5\% lived in neighborhoods within a radius of 100 meters from a bacilliferous child's house. The description of the main sociodemographic and cohousing variables is shown in table 1.

In the bivariate analysis, no associations were found between the explanatory variables and seropositivity rate for anti-NDO-LID antibodies in relation to household contacts. Regarding neighborhood contacts, brown race/skin color was inversely associated with $M$. leprae infection when compared to the other races $(\mathrm{PR}=0.24 ; 95 \% \mathrm{CI}: 0.06-0.87)$. More than 5 people per household (PR $=7.85 ; 95 \% \mathrm{CI}: 1.01-57.83)$ and households that had 2 or more children younger than 15 years ( $P R=3.34$; CI 95\%: 1.02-10.92) were associated with the highest seropositivity rates for anti-NDO-LID antibodies (Table 2). The variables associated with the prevalence of infection by $M$. leprae in all contacts were brown race/skin color (PR $=0.26$; 95\% CI: 0.09-0.66), urban residence area (PR $=1.09$; 95\% CI: 1.03-1.14), 2 or more people under the age of 15 in the house (PR = 3.37; 95\% CI: 1.05-8.56), and 5 or more people per household (PR = 7.58; $95 \%$ CI: 1.01-58.55).

The results of the final Poisson regression model can be visualized in table 3. The highest number of people per residence (PR $=8.71 ; 95 \%$ CI: 1.01-66.15) and brown race/skin color $(\mathrm{PR}=0.21$; 95\% CI: 0.59-0.80) were associated with seropositivity rate for anti-NDO-LID antibodies in neighborhood contacts. In relation to the multiple model that evaluated all contacts together (household and neighborhood contacts), the variables associated with the prevalence of leprosy bacillus infection were female sex (PR $=1.05$; 95\% CI: 1.01-1.08), non-brown race/skin color (PR = 0.95; IC95\%: 0.90-0.99), living in urban areas $(\mathrm{RP}=1.05 ; 95 \% \mathrm{CI}: 1.01-1.09)$, and a greater number of people per household ( $\mathrm{PR}=1.06$; $95 \% \mathrm{CI}$ : 1.02-1.08).

\section{DISCUSSION}

In this study, seropositivity rate for anti-NDO-LID antibodies in neighborhood contacts $(6.9 \%)$ was close to that observed in other studies and may be justified by leprosy hyperendemicity in the region. A study carried out in an area endemic of Goiânia, state of Goiás, indicated a positive rate of $5.3 \% .{ }^{9}$ In the hyperendemic area of Mato Grosso, the percentage of positive results to the rapid test was $14.7 \% .{ }^{14}$ However, in these works, the positive results were observed in household contacts, and the majority of them were 15 years old or older.

The higher prevalence of leprosy infection observed in neighborhood contacts can be explained by the contact these children and adolescents have with infected patients in their neighborhood, school, or other nearby environments. ${ }^{4,16}$ A study to assess anti-PGL-I levels conducted in an endemic region of Rio de Janeiro revealed similar serological positivity rates between peridomiciliary contacts $(15.6 \%)$ and household contacts $(15.8 \%) .{ }^{17}$ In Minas Gerais, a higher

TABLE 1: Distribution of household and neighborhood contacts under 15 years of age according to sociodemographic, cohabitational, and laboratorial variables, Cuiabá-MT, 2016

\begin{tabular}{ccccc} 
Variables & $\begin{array}{c}\text { Household } \\
\text { contacts } \\
(\mathrm{n}=50)\end{array}$ & $\begin{array}{c}\text { Neigh- } \\
\text { borhood } \\
\text { contacts } \\
(\mathrm{n}=160)\end{array}$ & $\begin{array}{c}\text { Total con- } \\
\text { tacts }(\mathrm{n}= \\
210)\end{array}$ \\
\hline $\mathrm{n} \quad \%$ & $\mathrm{n} \quad \%$ & $\mathrm{n}$ & $\%$
\end{tabular}

$\begin{array}{lllllll}\text { Age group } & & & & & & \\ 1-7 \text { years } & 17 & 34.0 & 81 & 50.6 & 98 & 46.7 \\ 8-14 \text { years } & 33 & 66.0 & 79 & 49.4 & 112 & 53.3 \\ \text { Sex } & & & & & & \\ \text { Male } & 20 & 40.0 & 86 & 53.8 & 106 & 50.5 \\ \text { Female } & 30 & 60.0 & 74 & 46.2 & 104 & 49.5\end{array}$

Race/Skin color

$\begin{array}{lcccccc}\text { Brown } & 29 & 58.0 & 96 & 60.0 & 125 & 59.5 \\ \text { Non brown } & 20 & 40.0 & 62 & 38.8 & 82 & 39.1 \\ \text { Ignored } & 1 & 2.0 & 2 & 1.2 & 3 & 1.4 \\ \text { Residence area } & & & & & & \\ \text { Urban } & 34 & 68.0 & 141 & 88.1 & 175 & 83.3 \\ \text { Rural } & 16 & 32.0 & 19 & 11.9 & 35 & 16.7\end{array}$

\# of people per household

\begin{tabular}{lcccccc}
$1-4$ & 15 & 30.0 & 69 & 43.1 & 84 & 40.0 \\
$\geq 5$ & 35 & 70.0 & 91 & 56.9 & 126 & 60.0 \\
$\begin{array}{l}\text { \# of people } \\
\text { under 15 years } \\
\text { in the house }\end{array}$ & & & & & & \\
$\geq 2$ & 23 & 46.0 & 105 & 65.6 & 128 & 60.9 \\
$>2$ & 27 & 54.0 & 55 & 34.4 & 82 & 39.1 \\
$\begin{array}{l}\text { Positive } \\
\text { serology }\end{array}$ & & & & & & \\
$\quad$ Yes & 2 & 4.0 & 11 & 6.9 & 13 & 6.2 \\
No & 48 & 96.0 & 149 & 93.1 & 197 & 93.8 \\
\hline
\end{tabular}

a This category includes white, black, Asians, and indigenous 
TABLE 2: Bivariate analysis of socioeconomic, demographic, and cohabitational variables associated with anti-NID-LID seropositivity in children under 15 years of age, contacts of leprosy patients, Cuiabá-MT, 2016

\begin{tabular}{|c|c|c|c|c|c|c|}
\hline \multirow[b]{2}{*}{ Variables } & \multicolumn{2}{|c|}{$\begin{array}{l}\text { Household } \\
\text { contacts }\end{array}$} & \multicolumn{2}{|c|}{$\begin{array}{l}\text { Neigh- } \\
\text { borhood } \\
\text { contacts }\end{array}$} & \multicolumn{2}{|c|}{ All contacts } \\
\hline & $\begin{array}{l}\text { PR- } \\
\text { gross }\end{array}$ & $\begin{array}{c}\text { IC } \\
95 \%\end{array}$ & $\begin{array}{l}\text { PR- } \\
\text { gross }\end{array}$ & $\begin{array}{c}\mathrm{IC} \\
95 \%\end{array}$ & $\begin{array}{l}\text { PR- } \\
\text { gross }\end{array}$ & $\begin{array}{c}\text { IC } \\
95 \%\end{array}$ \\
\hline
\end{tabular}

\section{Socioeconomic}

and

demographic

Age (years)

$1-7$

1.00

1.00

$8-14$

1.23

$0.31-\quad 1.40$

3.86

$0.47-$

4.13

Sex

Male
Female
Race/Skin
color $^{\mathbf{a}}$

Non brown ${ }^{a}$

Brown

1.00

$\begin{array}{lllll} & 1.00 & & 1.00 & \\ 0.04- & 3.09 & 0.85- & 3.18 & 0.87- \\ 10.05 & & 11.25 & & 11.54\end{array}$

11.54

\section{Residence area}

Rural

1.00

1.00

Urban

Housing

situation

Own a home

Rent a house/

live for free

Cohousing

\# of people per

household

1 - 4 years

1.00

1.00

1.00

$\geq 5$

0.42

0.02

7.85

$1.01-$

7.58

1.01 -

58.55

\# of people under 15 years in the house

\begin{tabular}{lccccccc}
$\geq 2$ & 1.00 & & 1.00 & \multicolumn{3}{r}{1.00} \\
$>2$ & 0.85 & $0.05-$ & 3.34 & $1.02-$ & 3.37 & $1.05-$ \\
& & 12.87 & & 10.92 & & 8.56
\end{tabular}

Length of resi-

dence $^{a}$

\begin{tabular}{lcccccc}
$<6$ years & 1.00 & & 1.00 & \multicolumn{3}{r}{1.00} \\
$\geq 6$ years & 0.72 & 0.04 & 0.51 & $0.14-$ & 0.52 & $0.14-$ \\
& & $-10-$ & & 1.87 & & 1.87 \\
& & 93 & & & &
\end{tabular}

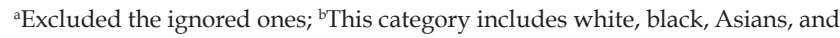
indigenous serology response for anti-NDO-LID antibodies was observed in the general population when compared to household contacts. ${ }^{12}$ In this context, since positive test results may mean a higher risk of early manifestation of the disease - especially in multibacillary cases epidemiological surveillance actions towards positive contacts may contribute to disrupt the transmission cycle and the development of the disease. Among these actions we can highlight bi-annual follow up for dermato-neurological evaluation, immunization with BCG vaccine, and screening of infected cases in the neighborhood and in schools.

The association between a greater number of people per household and urban residence with the highest seropositivity rates can be justified by the fact that precarious housing conditions and living in conglomerates of people are predictive factors for the development of leprosy, and express aspects of the social reality that circumscribe the disease occurrence. ${ }^{18-20}$ In fact, the literature indicates that the transmissibility and infectivity of $M$. leprae are higher in crowded places and may be related to physical and temporal proximity to the source of contamination. ${ }^{18,20,21}$ In this sense, the transmissibility of the disease was possibly influenced by the lower physical distances between untreated patients and susceptible individuals younger than 15 years of age. It may also have been influenced by precarious socio-sanitary conditions of the populations that live in the periphery of the cities. Moreover, it is pertinent to mention that individuals in the neighborhood played an important role in transmitting the infection to the child. ${ }^{3}$

We observed a prevalence of positive results among girls younger than 15 years of age. Similar to our research, a study carried out in the state of Minas Gerais, Brazil, with minors under 18 years of age, found a higher anti-PGL-I positivity among female contacts. ${ }^{22}$ Another study using PGL-I conducted among 6-18-year-old students and contacts of leprosy patients in an endemic region of the state of Pará found similar results in women. ${ }^{23}$ However, both studies failed to find statistically significant results. On the other hand, it should be mentioned that IgM levels tend to be higher in females than in males. ${ }^{24}$

The relationship observed in the bivariate analysis between seropositivity and the highest number of children under 15 years of age in the house, and the loss of association observed in the multiple analysis can be justified by the greater possibility of the family to have a greater agglomeration of people from other age groups. It is known that leprosy is common in people from disadvantaged social classes, with higher population densities per household, and insufficient education. ${ }^{16,23}$ The local epidemiological characteristics associated with the high magnitude of the disease in the region and the possibility of exogenous infection suggest regular exposure of the population to the bacillus. Thus, a high hidden prevalence of leprosy may be suspected. ${ }^{12,16}$ Moreover, the possibility of a greater susceptibility of children to leprosy infection due to immunological immaturity in this age group should also be considered., ${ }^{2,3}$

Self-reported brown skin color indicated a lower prevalence of leprosy when compared to non-brown skin color. A study carried out in the state of Mato Grosso in individuals with leprosy relapses found that the brown population was inversely associated with the higher prevalence of the disease. Therefore, the brown skin 
TABLE 3: Final multiple regression model of the variables associated with seropositivity rate for anti-NID-LID antibodies in children under 15 years of age, contacts of leprosy patients, Cuiabá-MT, 2016

\section{Household contacts}

Neighborhood contacts

All contacts

\begin{tabular}{|c|c|c|c|c|c|c|}
\hline Variables & PRADJUST (CI 95\%) & p-value & PRADJUST (CI 95\%) & p-value & PRADJUST (CI 95\%) & p-value \\
\hline \multicolumn{7}{|l|}{ Sex } \\
\hline Male & - & & - & & 1.00 & \\
\hline Female & - & ns & - & ns & $1.05(1.01-1.08)$ & 0.050 \\
\hline \multicolumn{7}{|c|}{ Race/Skin color ${ }^{\mathrm{a}}$} \\
\hline Non brown ${ }^{a}$ & - & & 1.00 & & 1.00 & \\
\hline Brown & - & ns & $0.21(0.59-0.80)$ & 0.022 & $0.95(0.90-0.99)$ & 0.027 \\
\hline \multicolumn{7}{|l|}{ Residence area } \\
\hline Rural & - & & - & & 1.00 & \\
\hline Urban & - & ns & - & ns & $1.05(1.01$ - 1.09) & 0.005 \\
\hline \multicolumn{7}{|l|}{$\begin{array}{l}\text { \# of people } \\
\text { per household }\end{array}$} \\
\hline $1-4$ & - & & 1.00 & & 1.00 & \\
\hline$\geq 5$ & - & ns & $8.71(1.01-66.15)$ & 0.049 & $1.06(1.02-1.08)$ & 0.007 \\
\hline
\end{tabular}

${ }^{\mathrm{a}}$ Excluded the ignored ones; ${ }^{\mathrm{b}}$ This category includes white, black, Asians, and indigenous; ns = non-significat

color seems to be a protection factor for the disease, in which relapses were $60 \%$ lower when compared to relapses in non-brown patients. ${ }^{15}$ Parsimony is recommended in the interpretation of these data since, apparently, there is no causal relation between race and disease resistance. Other factors, such as the higher prevalence of brown-skinned people in those states, may have influenced the outcome of the study. One possible interpretation that goes beyond the scope of the present study is that individuals with higher education levels tend to self-report their skin color more accurately. ${ }^{25}$ Another possible explanation lies in the fact that younger children may have been erroneously classified by parents or guardians in relation to skin color.

In the present study, the reduced sample size may have been a limitation for the identification of associated factors. It may also have contributed to the presence of wide confidence intervals. We also recommended parsimony in the interpretation of causality, since it is a cross-sectional study in which both exposure and outco- me factors were determined simultaneously. However, this study is a pioneer in identifying factors associated with positive results for the anti-NDO-LID rapid test in contacts under 15 years of age. It may be useful in subsidizing health interventions for early diagnosis and control of the disease in this specific group.

\section{CONCLUSION}

This study identified high seropositivity rates for anti-NDO-LID antibodies in contacts of leprosy patients. Living with five or more people, female sex, non-brown skin color, and living in the urban area were variables associated with positive rapid anti-NDO-LID test results in children under 15 years of age.

Our results point to the need for continuous monitoring of positive leprosy contacts, with bi-annual dermato-neurological evaluations. We also recommend the implementation of a BCG vaccination program and tracking of infected populations and cases in the neighborhood and in schools as measures to control the disease. $\square$ 


\section{REFERENCES}

1. Brasil. Ministério da Saúde. Secretaria de Vigilância em Saúde. Departamento de Vigilância das Doenças Transmissíveis. Diretrizes para vigilância, atenção e eliminação da Hanseníase como problema de saúde pública: manual técnico-operacional. Brasília: Ministério da Saúde; 2016.

2. Düppre NC, Camacho LA, Sales AM, Illarramendi X, Nery JA, Sampaio $E P$, et al. Impact of PGL-I Seropositivity on the Protective Effect of BCG Vaccination among Leprosy Contacts: A Cohort Study. PLoS Negl Trop Dis. 2012;6:e1711.

3. Rada E, Duthie MS, Reed SG, Aranzazu N, Convit J. Serologic followup of IgG responses against recombinant mycobacterial proteins ML0405, ML2331 and LID-1 in a leprosy hyperendemic area in Venezuela. Mem Inst Oswaldo Cruz. 2012;107(Suppl 1):S90-4.

4. Barbieri CLA, Marques HHS. Hanseníase em crianças e adolescentes: revisão bibliográfica e situação atual no Brasil. Pediatria. 2009;31:281-90

5. Freitas BHBM, Cortela DCB, Ferreira SMB. Tendência da hanseníase em menores de 15 anos em Mato Grosso (Brasil), 2001-2013. Rev Saúde Pública. 2017:51:28.

6. Who.int [Internet]. World Health Organization. Global leprosy update, 2015: time for action, accountability and inclusion. Weekly Epidemiological Record, n 35, 2 September 2016 [cited 2016 Nov 02]; 91:405-420. Available from: http://www.who.int/wer/2016/ wer9135/en/

7. Sage.saude.gov [Intrnet]. Sala de Apoio a Gestão Estratégica do Ministério da Saúde. Situação de Saúde: indicadores de morbidade. Hanseníase [cited 2016 Jun 10]. Available from: http://sage.saude. gov.br/

8. Secretaria Estadual de Saúde de Mato Grosso. Departamento de Vigilância Epidemiológica. Sistema de Informação de Agravos de Notificação de Mato Grosso; 2016.

9. Paula Vaz Cardoso L, Dias RF, Freitas AA, Hungria EM, Oliveira RM Collovati $\mathrm{M}$, et al. Development of a quantitative rapid diagnostic test for multibacillary leprosy using smart phone technology. BMC Infect Dis. 2013;13:497.

10. Duthie MS, Balagon MF, Maghanoy A, Orcullo FM, Cang M, Dias RF, et al. Rapid quantitative serological test for detection of infection with Mycobacterium leprae, the causative agent of leprosy. J Clin Microbiol. 2014;52:613-9.

11. Amorim FM, Nobre ML, Ferreira LC, Nascimento LS, Miranda AM, Monteiro GR, et al. Identifying Leprosy and Those at Risk of Developing Leprosy by Detection of Antibodies against LID-1 and LID-NDO. PLoS Negl Trop Dis. 2016;10:e0004934.

12. da Conceição Oliveira Coelho Fabri A, Carvalho AP, Araujo S, Goulart LR, de Mattos AM, Teixeira HC et al. Antigen-specific assessment of the immunological status of various groups in a leprosy endemic region. BMC Infect Dis. 2015;15:218.
13. Duthie MS, Raychaudhuri R, Tutterrow $Y L$, Misquith A, Bowman J, Casey $A$, et al. A rapid ELISA for the diagnosis of MB leprosy based on complementary detection of antibodies against a novel proteinglycolipid conjugate. Diagn Microbiol Infect Dis. 2014;79:233-9.

14. Silva EA. Avaliação e monitoramento dos contatos intradomiciliares de pacientes com hanseníase: sorologia para detecção de anticorpos anti-PGL-I e avaliação da reatividade a proteínas recombinantes do Mycobacterium leprae [Tese]. São Paulo (SP): Universidade Federal de São Paulo; 2016. 112p.

15. Ferreira $\mathrm{SMB}$, Ignotti $\mathrm{E}$, Gamba MA. Fatores associados à recidiva em hanseníase em Mato Grosso. Rev Saúde Pública. 2011;45:756-64.

16. Barreto JG, Bisanzio D, Guimarães Lde S, Spencer JS, VazquezProkopec GM, Kitron U, et al. Spatial analysis spotlighting early childhood leprosy transmission in a hyperendemic municipality of the Brazilian Amazon Region. PLoS Negl Trop Dis. 2014;8:e2665.

17. Calado KLS, Vieira AG, Durães S, Buhrer-Sékula S, Oliveira MLWDR. Seropositivity with anti-PGL- I of household and neighbours contacts of leprosy patients in an urban área. An Bras Dermatol. 2005; 80 (Suppl 3):S301-306.

18. Carvalho AP, da Conceição Oliveira Coelho Fabri A, Corrêa Oliveira $\mathrm{R}$, Lana FC. Factors associated with anti-phenolic glycolipidseropositivity among the household contacts of leprosy cases. BMC Infect Dis. 2015;15:219.

19. Bakker MI, Hatta M, Kwenang A, Van Mosseveld P, Faber WR, Klatser $\mathrm{PR}$, et al. Risk factors for developing leprosy: a population-based cohort study in Indonesia. Lepr Rev. 2006;77:48-61.

20. Santos AS, Castro DS, Falqueto A. Fatores de risco para transmissão da Hanseníase. Rev Bras Enferm. 2008;61:738-43.

21. Moet FJ, Pahan D, Schuring RP, Oskam L, Richardus JH. Physical distance, genetic relationship, age, and leprosy classification are independent risk factors for leprosy in contacts of patients with leprosy. J Infect Dis. 2006;193:346-53.

22. Ferreira MAA, Antunes CMF. Fatores associados à soropositividade do teste ML Flow em pacientes e contatos de pacientes com hanseníase menores de 18 anos. Rev Soc Bras Med Trop. 2008; 41(Suppl 2):S60-6.

23. Barreto JG, Guimarães Lde S, Leão MR, Ferreira DV , Lima RA, Salgado CG. Anti-PGL-I seroepidemiology in leprosy cases:household contacts and school children from a hyperendemic municipality of the Brazilian Amazon. Lepr Rev. 2011;82:358-70.

24. Oskam L, Slim E, Bührer-Sékula S. Serology: recent developments, strengths, limitations and prospects: a state of the art overview. Lepr Rev. 2003;74:196-205.

25. Camarano AA, Kanso, S. Envelhecimento da população brasileira: uma contribuição demográfica. In: Freitas EV e Py L, editores. Tratado de Geriatria e Gerontologia. 3. ed. reimp. Rio de Janeiro: Guanabara Koogan; 2013. p. 133-52. interpreting the data; effective participation in research orientation; intellectual participation in the propaedeutic and/or therapeutic approach of the studied cases; critical review of the literature; critical review of the manuscript.

Denise da Costa Boamorte Cortela in research orientation; intellectual participation in the propaedeutic and/or therapeutic approach of the studied cases; critical review of the literature; critical review of the manuscript. in research orientation; intellectual participation in the propaedeutic and/or therapeutic approach of the studied cases; critical review of the literature; critical review of the manuscript.

Ageo Mário Cândido da Silva $\quad$ (D) ORCID 0000-0001-5293-9413

Statistical analysis; approval of the final version of the manuscript; conception and planning of the study; obtaining, analyzing and interpreting the data; effective participation in research orientation; intellectual participation in the propaedeutic and/or therapeutic approach of the studied cases; critical review of the literature; critical review of the manuscript.

Silvana Margarida Benevides Ferreira (D) ORCID 0000-0001-7421-5803

Statistical analysis; approval of the final version of the manuscript; conception and planning of the study; elaboration and writing of the manuscript; obtaining, analyzing and interpreting the data; effective participation in research orientation; intellectual participation in the propaedeutic and/or therapeutic approach of the studied cases; critical review
} of the literature; critical review of the manuscript.

How to cite this article: Gomes LC, Cortela DCB, Silva EA, Silva AMC, Ferreira SMB. Leprosy: prevalence and factors associated with seropositivity for anti-NDO-LID antibodies in children under 15 years of age. An Bras Dermatol. 2019;94(4):405-10. 